\title{
Microbial community profiling - applications in plant protection
}

\author{
E.M. Gerard, J. Monk, S.A. Wakelin and M. O’Callaghan \\ AgResearch, Lincoln, Private Bag 4749, Christchurch 8140, New Zealand \\ Corresponding author: emily.gerard@agresearch.co.nz
}

The function and diversity of microbial communities associated with plants, insects and soils directly impacts on plant health and production. Although community level investigations appear daunting, significant gains are being made through the application of molecular biology. An important technique involves polymerase chain reaction (PCR) amplification of genes from DNA/RNA isolated from the environment, removing limitations caused by microbial cultivation. PCR amplicons are then separated using denaturing gradient gel electrophoresis (DGGE) providing a 'fingerprint' of the diversity of that gene within the microbial community. This PCR-DGGE based method originally targeted the ribosomal RNA (rRNA) genes present in all microorganisms. Other genetic markers are now used, including general markers coding for conserved proteins involved in core cell functions, or genes essential to activities defining specific functional groups, such as ammonia oxidation, nitrogen fixation or antibiotic production. Reverse-transcription PCR-DGGE on community RNA can be used to profile metabolically active populations. PCR-DGGE allows for the rapid comparison of multiple samples and, when used in combination with other approaches, provides robust information of environmental microbial communities. Recent uses in plant protection research include examination of: effects of pesticides and biocontrol agents on microbial populations, soil disease suppression, plant rhizosphere communities, microbe-mineral interactions, microbe-insect interactions, insect microbiota, predatorprey studies and community responses to changing farming practices.

\section{Detecting benzimidazole resistance in Botrytis allii using molecular techniques}

\author{
M-I. Khan, S.R. Bulman, S.L.H. Viljanen-Rollinson, V.M. Marroni and I.A.W. Scott \\ The New Zealand Institute for Plant E Food Research Limited, Private Bag 4704, Christchurch, \\ New Zealand \\ Corresponding author:Ikram.Khan@plantandfood.co.nz
}

Neck rot, caused by Botrytis allii, is an important storage disease of onions. Fungicides, including benzimidazoles, have been used as seed treatments and crop applications to control this disease during seed and bulb production. Resistance to benzimidazole fungicides has been previously reported in $B$. allii from New Zealand. Five sensitive and five resistant isolates of the pathogen were grown in culture for DNA extraction and analysis of sequences of $\beta$-tubulin fragments. Sequence analysis revealed a single point mutation in the $\beta$-tubulin gene in the resistant isolates. PCR primers to detect the mutation were designed and tested, and these clearly differentiated resistant from sensitive isolates. The PCR test developed in this study will allow rapid and cost-effective screening of $B$. allii isolates to determine their sensitivity to benzimidazole fungicides. The test provides technology that will assist in the development of fungicide resistance management tools for onion crops. 